Research Article

\title{
Simplified Analytical Method for Predicting the Lateral Ground Displacements due to Shield Tunnelling
}

\author{
Lianwei Sun (i), ${ }^{1}$ Zhong-chao $\mathrm{Li}^{2}$ and Rong-zhu Liang ${ }^{3}{ }^{3}$ \\ ${ }^{1}$ Shanghai Construction Group Co., Ltd., Shanghai 200080, China \\ ${ }^{2}$ Wuhan Municipal Construction Group Co., Ltd., Wuhan 340023, Hubei, China \\ ${ }^{3}$ China University of Geosciences (Wuhan), Faculty of Engineering, Wuhan 430074, China \\ Correspondence should be addressed to Rong-zhu Liang; liangcug@163.com
}

Received 22 February 2021; Revised 21 May 2021; Accepted 9 June 2021; Published 22 June 2021

Academic Editor: Xin-Jiang Wei

Copyright (C) 2021 Lianwei Sun et al. This is an open access article distributed under the Creative Commons Attribution License, which permits unrestricted use, distribution, and reproduction in any medium, provided the original work is properly cited.

Earth pressure balance or slurry shield tunnelling will squeeze the subsoils and lead to lateral outward ground displacement. However, current methods to estimate the shield tunnelling-induced ground displacements generally use the methods based on the face unsupported tunnelling (e.g., New Austrian tunnelling and open shield excavation), which cannot predict the lateral ground movement due to shield tunnelling. In this paper, a novel simplified analytical method is proposed to predict the ground lateral displacement during the shield advancing process. The key shield tunnelling operation factors, including the additional pressure of cutter head, the friction forces around shield body, the back-fill grouting pressure, and the soil volume loss are all considered. The lateral ground displacements induced by the four former factors are calculated by using Mindlin's solutions. The soil volume loss-induced lateral ground displacement is calculated by employing the expression introduced by Pinto and Whittle. Combining with the displacement obtained from all the factors, the analytical method for lateral ground displacement induced by shield tunnelling is obtained. The applicability of the proposed analytical approach is verified with three well-documented case histories involving slurry shield and EPB shield machines.

\section{Introduction}

Earth pressure balance (EPB) or slurry shield tunnelling technology has advantage of rapid construction efficiency and minor environment disturbance, which is widely used in metro tunnel construction in densely urban area. However, the shield tunnelling method is kind of a face pressured tunnelling method, which will squeeze the ground and lead to large horizontal ground displacement. The ground movement mechanisms associated with shield tunnelling are totally different from the face unsupported tunnelling, such as New Austrian tunnelling and open shield excavation, in which the inward ground movements are usually observed because of none face pressure or grouting pressure imposing on the excavation face. Therefore, accurate evaluation of the shield tunnellinginduced ground deformation is vital before assessment of the adverse effects on adjacent buildings and the nearby underground utilities (e.g., shallow foundations, exiting tunnels, piles, and gas pipelines).

During the last decades, various approaches have been established for predicting the ground deformation associated with space unsupported tunnelling methods, namely, empirical method, analytical method, and finite-element method [1-11]. Peck [1] and Attewell and Woodman [2] indicated that the ground surface movement profile-induced tunnel excavation can be empirically described using Gaussian distribution curve. Mair et al. [3] and Fang et al. [4] further modified and improved the Peck formula and applied to predict the subsurface settlement caused by tunnel excavation. In recent years, lots of analytical methods have been established to predict the tunnelling-induced displacements. Sagaseta [5] and Verruijt and Booker [6] presented closed-form solutions for three-dimensional soil movements induced by tunnelling-caused soil loss in isotropic incompressible ground and compressible ground, 
respectively. Loganathan and Polous [7] redefined equivalent ground loss and proposed a new analytical method to calculate the vertical and lateral soil movements in nonuniform convergence pattern. Bobet [8] and Osman et al. [9] deduced a series of solutions for two-dimensional soil movements based on the elasticity theory. The abovementioned analytical solutions are more suitable for estimating the ground movement associated with face unsupported tunnelling. Franza and Marshall [10] proposed empirical and semianalytical methods for evaluating the ground settlements induced by tunnelling in sands. Zhang et al. [11] proposed a closed-form elastic analytical solution for prediction of the tunnelling-ground displacement. However, the detailed observations from San Francisco [12], London [13], Shanghai [14], France [15], and Taipei [16] indicated that heaves and outward ground movements were always observed during tunnel excavation by using the advanced shield tunnelling methods (EPB and slurry shield machines). The main reason for the difference is due to the mechanization of shield tunnelling procedures. During the shield tunnelling, the subsoil is excavated by rotating cutter head. Then, the shield moves forwards by hydraulic jacks. Finally, back-fill grouting is carried out to fill the construction gap. All the procedures may lead to ground displacement which makes the ground movement pattern quite different from that of conventional tunnelling. Therefore, a suitable analytical method is urgently needed to reliably predict ground displacements due to shield tunnelling.

With the development of computer technology, the nonlinear finite-element analysis (FEA) has been carried out to simulate the entire tunnelling excavation process. Lee and Rowe [17] performed a 3D elastoplastic FE analysis to investigate the effects of shield tunnelling on the surface and subsurface ground movements. Dias and Kastner [15] established 3D finite-element models to simulate the slurry shield excavation processes in tunnel projects in France and China, respectively. Undoubtedly, the FEA is a direct method to model the $3 \mathrm{D}$ soil deformations, as well as tunnelling stages. Yiu et al. [18] explored the masonry building responses to shallow tunnelling using $3 \mathrm{D}$ finite-element modelling. Zhang et al. [19] established a 3D fluid-solid coupling finite-element model to investigate the unexpected ground settlement when the shield machine advanced from the low-permeability ground to the highpermeability ground.
In this paper, a novel simplified analytical method is proposed to predict the lateral ground displacements caused by shield tunnelling in soft ground. The key shield tunnelling operation parameters such as additional pressure of cutter head, the frictions around shield shell, the grout injection pressure, and the soil volume loss are taken into account in the proposed method to consider the shield tunnel construction performance. The proposed analytical method is verified against three well-documented case histories in San Francisco tunnel, Shanghai Metro Line-2 tunnel, and France Vaise subway tunnel.

\section{Simplified Analytical Method for Predicting Lateral Ground Movement Induced by Shield Tunnelling}

The mechanism of the interaction between shield tunnelling excavation and soil surrounding is highly complex. The ground deformation is mainly influenced additional pressures of cutter-head $q$, frictions around shied shell skin $f$, the tail grouting pressure $p$, and the soil volume loss $v_{l}$ during shield machine advancing. Therefore, the four main influencing factors are considered in the proposed method. Figure 1 shows the mechanical model of shield tunnelling in ground. The lateral ground displacements induced by the variants of $q, f$, and $p$ are estimated by using Mindlin's solutions [20]. The analytical solutions suggested by Pinto and Whittle [21] are applied to compute the lateral ground displacements caused by the soil volume loss $v_{l}$. Finally, the total lateral displacements can be estimated by superposing the results calculated by these separated variants. In the proposed method, the lateral displacement induced by shield tunnelling at transversal and longitudinal directions is considered.

Shield machine usually advances at a shallow depth, and the ground displacements caused by the variants $q$, $f$, and $p$ are typical semi-infinite problems. Correspondingly, semiinfinite Mindlin's solutions [20] are selected to calculate the ground displacements caused by the variants $q, f$, and $p$ in this analysis. A concentrated force $p_{\mathrm{h}}$ parallel to the surface boundary acting at a point in the interior of a half-space is shown in Figure 2.

The response of lateral displacements at both longitudinal and transversal directions to the horizontal concentrated force $P_{\mathrm{h}}$ is expressed as follows:

$$
\begin{aligned}
& v_{h}=\frac{P_{\mathrm{h}} x^{\prime} y^{\prime}}{16 \pi G(1-\mu)}\left[\frac{1}{R_{1}^{3}}+\frac{3-4 \mu}{R_{2}^{3}}-\frac{6 c z^{\prime}}{R_{2}^{5}}-\frac{4(1-\mu)(1-2 \mu)}{R_{2}\left(R_{2}+z^{\prime}+c\right)^{2}}\right], \\
& u_{h}=\frac{P_{\mathrm{h}}}{16 \pi G(1-\mu)}\left\{\frac{3-4 \mu}{R_{1}}+\frac{1}{R_{2}}+\frac{x^{\prime 2}}{R_{1}^{3}}+\frac{(3-4 \mu) x^{\prime 2}}{R_{2}^{3}}+\frac{2 c z^{\prime}}{R_{2}^{3}}\left(1-\frac{3 x^{\prime 2}}{R_{2}^{2}}\right)+\frac{4(1-\mu)(1-2 \mu)}{R_{2}+z^{\prime}+c}\left[1-\frac{x^{\prime 2}}{R_{2}\left(R_{2}+z^{\prime}+c\right)}\right]\right\}
\end{aligned}
$$




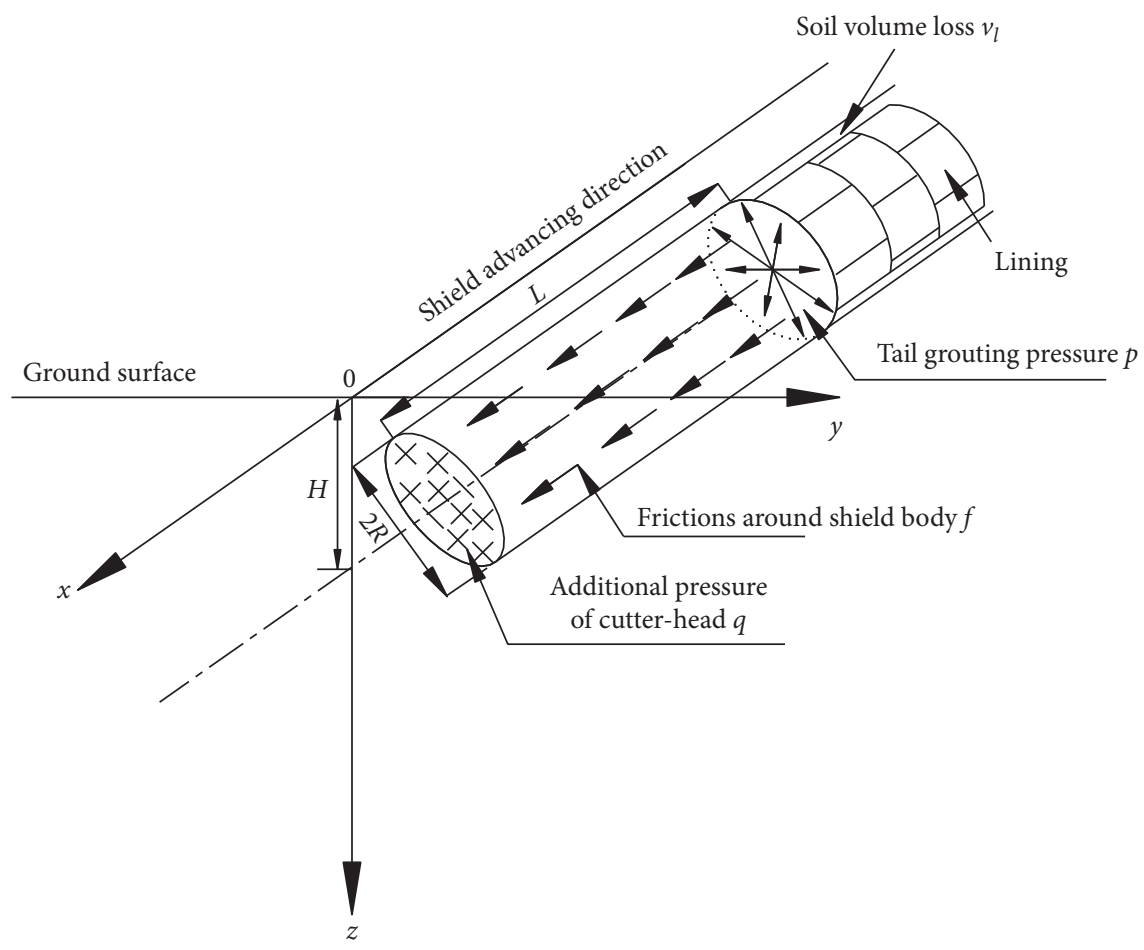

FIGURE 1: Mechanical model of shield tunnelling in soft ground.

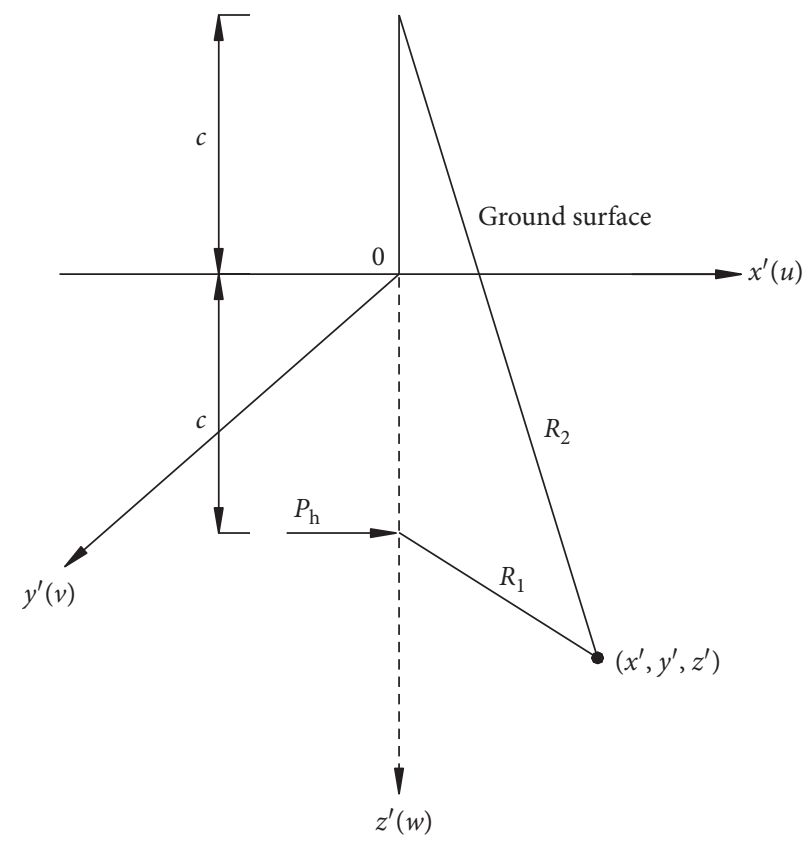

FIGURE 2: Mindlin's solutions of a concentrated force acting at a point in the interior of half-space solid parallel to the ground surface. 
where $v_{h}$ and $u_{h}$ are the lateral displacements in longitudinal and transversal directions, respectively. $\mu$ is Poisson's ratio; $G$ is the shear modulus. $R_{1}=\sqrt{x^{\prime 2}+y^{\prime 2}+\left(z^{\prime}-c\right)^{2}}$, $R_{2}=\sqrt{x^{\prime 2}+y^{\prime 2}+\left(z^{\prime}+c\right)^{2}}$.
2.1. Lateral Ground Displacements Induced by the Additional Pressure of Cutter-Head q. Figure 3 shows the sketch of integration of additional pressure of cutter head. The lateral displacements at both longitudinal and transversal directions induced by additional pressure of cutter-head $q$ are obtained by integrating (1) and (2), respectively:

$$
\begin{aligned}
u_{1 q}= & \int_{0}^{R} \int_{0}^{2 \pi} q r \mathrm{~d} r \mathrm{~d} \theta \frac{1}{16 \pi G(1-\mu)}\left\{\frac{3-4 \mu}{R_{1}}+\frac{1}{R_{2}}+\frac{x^{2}}{R_{1}^{3}}+\frac{(3-4 \mu) x^{2}}{R_{2}^{3}}+\frac{2(H-r \sin \theta) z}{R_{2}^{3}}\left(1-\frac{3 x^{2}}{R_{2}^{2}}\right)\right. \\
& \left.+\frac{4(1-\mu)(1-2 \mu)}{R_{2}+z+(H-r \sin \theta)}\left[1-\frac{x^{2}}{R_{2}\left(R_{2}+z+H-r \sin \theta\right)}\right]\right\}, \\
v_{1 q}= & \int_{0}^{R} \int_{0}^{2 \pi} q r \mathrm{~d} r \mathrm{~d} \theta \frac{x(y-r \sin \theta)}{16 \pi G(1-\mu)}\left[\frac{1}{R_{1}^{3}}+\frac{3-4 \mu}{R_{2}^{3}}-\frac{6(H-r \sin \theta) z}{R_{2}^{5}}-\frac{4(1-\mu)(1-2 \mu)}{R_{2}\left(R_{2}+z+H-r \sin \theta\right)^{2}}\right],
\end{aligned}
$$

where $u_{1 q}$ and $v_{1 q}$ are the lateral displacements at both longitudinal and transversal directions, respectively; $R$ is the radius of cutter head; $R_{1}$ and $R_{2}$ can be expressed as $R_{1}=\sqrt{x^{2}+(y-r \cos \theta)^{2}+(z-H+r \sin \theta)^{2}}$ and $R_{2}=$ $\sqrt{x^{2}+(y-r \cos \theta)^{2}+(z+H-r \sin \theta)^{2}}$, respectively.

The additional face pressure $q$ is assumed to be distributed uniformly at the cutter head. For a tunnel constructed by a slurry shield tunnel machine, the additional pressure of cutter-head $q$ can be regarded as the difference between the measured slurry pressure $p_{s l}$ and the in situ earth pressure at rest $K_{0} \gamma H$ at the depth of tunnel axis:

$$
q=p_{s l}-K_{0} \gamma H
$$

where $K_{0}$ is the coefficient of lateral earth pressure at rest; $\gamma$ and $H$ are the representative unit weight and the depth from the ground surface to the spring-line of the tunnel, respectively.

However, for tunnel constructed by an EPB machine, Standing et al. [22] found the ground moved outward was measured and the pore-water pressures continuously increased in spite of the fact that the measured earth pressures at the soil chamber were significantly lower than the earth pressure at rest. Standing et al. [22] indicated that the actual normal stresses at cutter head were much larger than the measured earth pressure at the soil chamber. This phenomenon can be interpreted as ground squeezing effect caused by the rotating cutter head of EPB machine [23]. Taking the key cutting parameters and ground conditions into consideration, Wang [23] presented a theoretical solution to calculate the squeezing normal stress ahead of the cutter head. In this study, the squeezing normal stress is taken as the additional pressure of the cutter-head $q$ :

$$
q=\frac{10.13(1-\mu) E_{\mathrm{u}} \pi \nu(1-\xi)^{2}}{(1+\mu)(3-4 \mu) D k w}+\Delta p^{\prime}
$$

where $E_{\mathrm{u}}$ is undrained Young's modulus of soil; $v$ is the driving rate of the shield; $\xi$ is the open ratio of the cutter head; $D$ is the diameter of the cutter head; $k$ is number of the blind slots; $w$ is the angular speed; and $\Delta p$ ' is the squeezing pressure at the opening of cutter head, ranging from $10 \mathrm{kPa}$ to $20 \mathrm{kPa}$.

The operation parameters, such as the driving rate $v$ and the rotating rate $w$, are continuously recorded during the advancing. Undrained Young's modulus of soil $E_{\mathrm{u}}$ in clayey ground can be obtained by the approximately relation between $E_{\mathrm{u}}$ and the undrained shear strength $c_{\mathrm{u}}$ as $E_{\mathrm{u}}=350 c_{\mathrm{u}}$ [24].

2.2. Lateral Ground Displacements Induced by the Frictions around Shield Bodyf. The frictions around shield body $f$ are generated by the interaction between the moving shield body and the contacted soils. As shown in Figure 4, it is assumed that the frictions around shield body $f$ are distributed uniformly in the longitudinal direction along the shield body, but nonuniformly around the shield periphery. The lateral ground displacements at longitudinal and transversal directions induced by the frictions around shield body $f$ are obtained by integrating (1) and (2), respectively, as follows: 


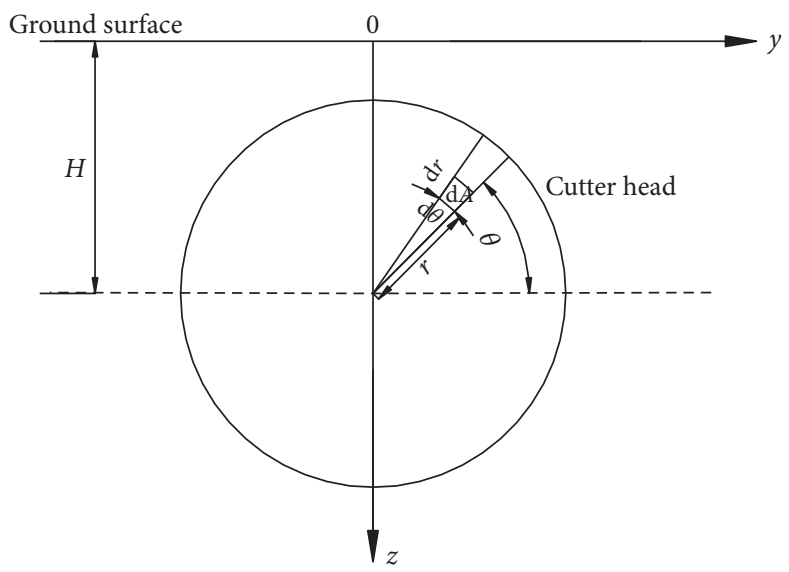

Figure 3: The sketch of integration of additional pressure of cutter head.

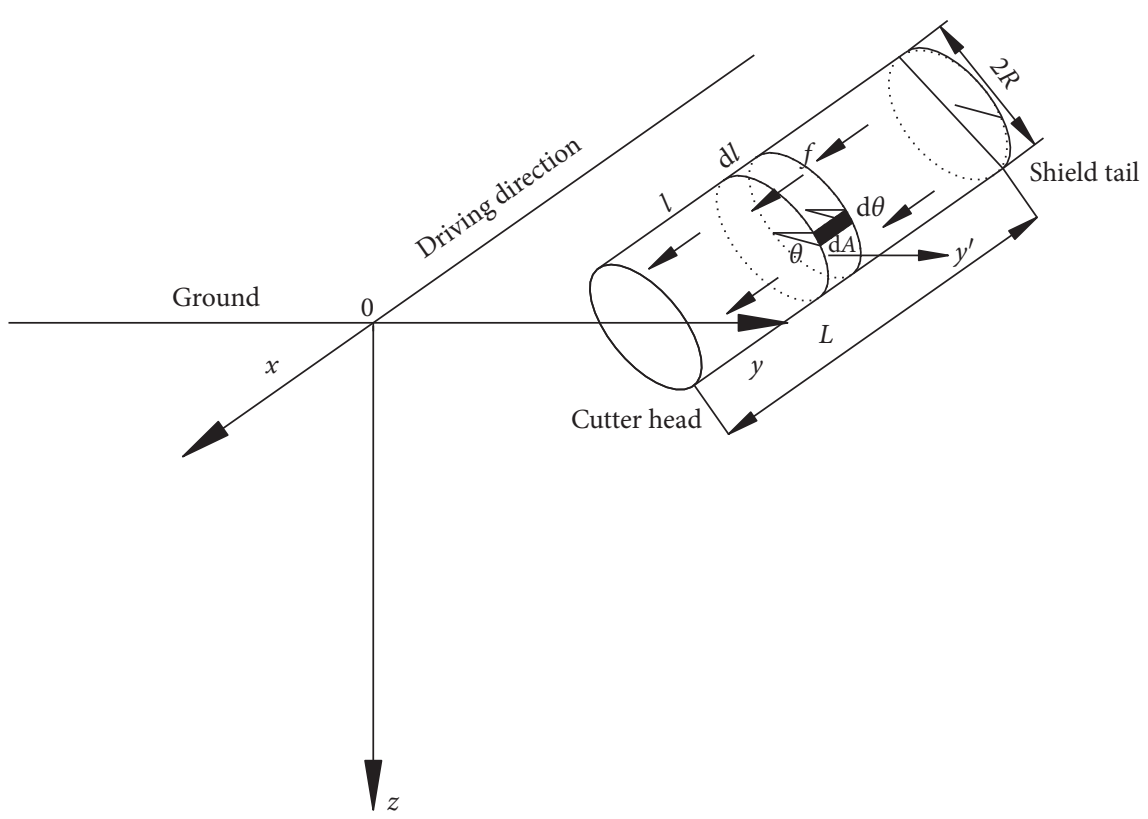

Figure 4: The relation of the global and local coordinate system and the sketch of frictions around the shield body.

$$
\begin{aligned}
& u_{2 f}=\int_{0}^{2 \pi} \int_{0}^{L} \frac{f R \mathrm{~d} l \mathrm{~d} \theta}{16 \pi G(1-\mu)}\left\{\frac{3-4 \mu}{R_{1}}+\frac{1}{R_{2}}+\frac{(x+l)^{2}}{R_{1}^{3}}+\frac{(3-4 \mu)(x+l)^{2}}{R_{2}^{3}}+\frac{2(H-R \sin \theta) z}{R_{2}^{3}}\left(1-\frac{3(x+l)^{2}}{R_{2}^{2}}\right)\right. \\
& \left.+\frac{4(1-\mu)(1-2 \mu)}{R_{2}+z+(H-R \sin \theta)}\left[1-\frac{(x+l)^{2}}{R_{2}\left(R_{2}+z+H-R \sin \theta\right)}\right]\right\}, \\
& \qquad v_{2 f}=\int_{0}^{2 \pi} \int_{0}^{L} \frac{f R \mathrm{~d} l \mathrm{~d} \theta(x+l)(y-R \sin \theta)}{16 \pi G(1-\mu)}\left[\frac{1}{R_{1}^{3}}+\frac{3-4 \mu}{R_{2}^{3}}-\frac{6(H-R \sin \theta) z}{R_{2}^{5}}-\frac{4(1-\mu)(1-2 \mu)}{R_{2}\left(R_{2}+z+H-R \sin \theta\right)^{2}}\right], \\
& \text { where } L \text { is the length of shield shell; } u_{2 f} \text { and } v_{2 f} \text { are the } \\
& \text { lateral ground displacements in the longitudinal and } \\
& \text { grans }
\end{aligned}
$$
transversal directions, respectively; $R_{1}$ is equal to $\sqrt{(x+l)^{2}+(y-R \cos \theta)^{2}+(z-H+R \sin \theta)^{2}} ; R_{2}$ is equal to $\sqrt{(x+l)^{2}+(y-R \cos \theta)^{2}+(z+H-R \sin \theta)^{2}}$.

The friction around shield body $f$ is estimated by where $\tau_{s r}$ is the residual shear force at the pile-soil interface; $\beta_{s}$ is the softening coefficient, which is defined as the ratio of the residual shear force $\tau_{s r}$ to the ultimate shear force $\tau_{u}$ at the steel-soil interface. Its value varies from 0.83 to 0.97 for 
soft soils [25]. $\delta$ is the interior angel between the shield shell and the contacted soils, which is presented in Table 1 based on Alonso et al.'s [26] interface shearing experiments.

$\sigma_{\theta}$ is the normal stress acting on the shield body:

$$
\sigma_{\theta}=\sigma_{v} \sin ^{2} \theta+\sigma_{h} \cos ^{2} \theta,
$$

where $\sigma_{v}$ and $\sigma_{h}$ are the vertical and horizontal effective stresses acting on the shield body, respectively:

$$
\begin{aligned}
& \sigma_{v}=\sigma_{t}-\gamma R \sin \theta, \\
& \sigma_{h}=K_{0} \sigma_{v},
\end{aligned}
$$

where $\sigma_{t}$ is the vertical earth stress at the shield axis.

\subsection{Lateral Ground Displacements Induced by the Tail} Grouting Pressure $p$. As the shield moves forward, the grouting materials are injected synchronously to fulfill the annual void between the segmental lining and the excavation face. The back-fill grouting can effectively prevent the ground moving into the annual void. However, when the tail grouting pressure $p$ is larger than the in situ earth pressure (both vertical and horizontal), the surrounding ground will be pushed away laterally and ground upheaval and outward
TABLE 1: The value of interface friction angle $\delta$ between different soils and smooth steel material.

\begin{tabular}{lc}
\hline Type of soils & Interface angel \\
\hline Clays & $6.5^{\circ} \sim 9^{\circ}$ or $0.55 \sim 0.56 \phi^{\prime *}$ \\
Sands & $23.5^{\circ} \sim 24^{\circ}$ or $0.55 \sim 0.64 \phi^{\prime *}$ \\
Clayey gravel & $7.5^{\circ} \sim 9.5^{\circ}$ or $0.44 \sim 0.58 \phi^{\prime *}$ \\
\hline
\end{tabular}

${ }^{*} \phi^{\prime}$ is the effective interior angle of soil.

displacements occur. Therefore, the effects of tail grouting on the ground movements should be considered.

Figure 5 illustrates the calculation model of the lateral ground displacements induced by the tail grouting pressure $p$. It is assumed that the grouting pressure distributes uniformly around the shield tail periphery and the grouting length is equal to the width of the segmental lining. In reality, the tail grouting pressure $p$ is continuously monitored during the shield advancing.

It is noted that the grouting pressure has little influence on the lateral ground displacement at longitudinal direction. Therefore, lateral ground displacement at longitudinal direction is not considered in this analysis. Based on Mindlin's solutions, the lateral displacements at transversal direction are obtained as follows:

$$
\begin{aligned}
v_{3 p}= & \int_{0}^{S} \int_{0}^{2 \pi} \frac{\left(p-\sigma_{\theta}\right) \cos \theta R \mathrm{~d} s \mathrm{~d} \theta}{16 \pi G(1-\mu)}\left\{\frac{3-4 \mu}{R_{1}}+\frac{1}{R_{2}}+\frac{(y-R \cos \theta)^{2}}{R_{1}^{3}}+\frac{(3-4 \mu)(y-R \cos \theta)^{2}}{R_{2}^{3}}\right. \\
& \left.+\frac{2(H-R \sin \theta) z}{R_{2}^{3}}\left[1-\frac{3(y-R \cos \theta)^{2}}{R_{2}^{2}}\right]+\frac{4(1-\mu)(1-2 \mu)}{R_{2}+z+H-R \sin \theta}\left[1-\frac{(y-R \cos \theta)^{2}}{R_{2}\left(R_{2}+z+H-R \sin \theta\right)}\right]\right\},
\end{aligned}
$$

where $S$ is the influencing length of grouting. As mentioned above, $S$ is taken as the width of segmental lining. $R_{1}$ is equal to $\sqrt{(y-R \cos \theta)^{2}+(x+L+s)^{2}+(z-H+R \sin \theta)^{2}}$, and $R_{2}$ is equal to $\sqrt{(y-R \cos \theta)^{2}+(x+L+s)^{2}+(z+H-R \sin \theta)^{2}}$.

2.4. Lateral Ground Displacements Induced by the Soil Volume Loss $v l$. Many studies have been proposed to estimate the lateral soil displacements associated with tunnelling-induced soil losses [7-11]. However, all of these methods offer two-dimensional solutions, which are unable to capture the three-dimensional behavior of soil deformations associated with shield tunnelling. In this study, three-dimensional analytical solutions introduced by Pinto and Whittle [21] are applied to predict the lateral ground displacements.

Assuming the soil volume loss distributed uniformly along the tunnel axis, Pinto and Whittle [21] deduced threedimensional closed-form solutions for ground displacements induced by the soil volume losses. The lateral ground displacement solutions in both longitudinal and transversal directions of shield advancing are given as follows:

$$
\begin{aligned}
& u_{4 v_{l}}=\frac{v_{l}}{4 \pi}\left\{\frac{1}{R_{11}}+\frac{(3-4 \mu)}{R_{22}}-\frac{2 z(z-H)}{R_{22}^{3}}\right\}, \\
& v_{4 v_{l}}=\frac{v_{l}}{4 \pi}\left\{\frac{y\left[R_{11}-(x+L)\right]}{r_{1}^{2} R_{11}}+\frac{(3-4 \mu) y\left[R_{22}-(x+L)\right]}{r_{2}^{2} R_{22}}+\frac{y z(z+H)\left\{2(x+L)\left[3 R_{22}^{2}-(x+L)^{2}\right]-4 R_{22}^{3}\right\}}{r_{2}^{4} R_{22}^{3}}\right\},
\end{aligned}
$$

where $u_{4 v_{l}}$ and $v_{4 v_{l}}$ are the lateral ground displacements in both longitudinal and transversal directions of shield advancing, respectively; $v_{l}$ is the soil volume loss, $v_{l}=2 \pi R u_{\varepsilon}$, where $u_{\varepsilon}$ is the distance between the segmental lining and the excavated soils in uniform convergence pattern. The correlation between the soil volume loss $v_{l}$ and the ratio of soil 


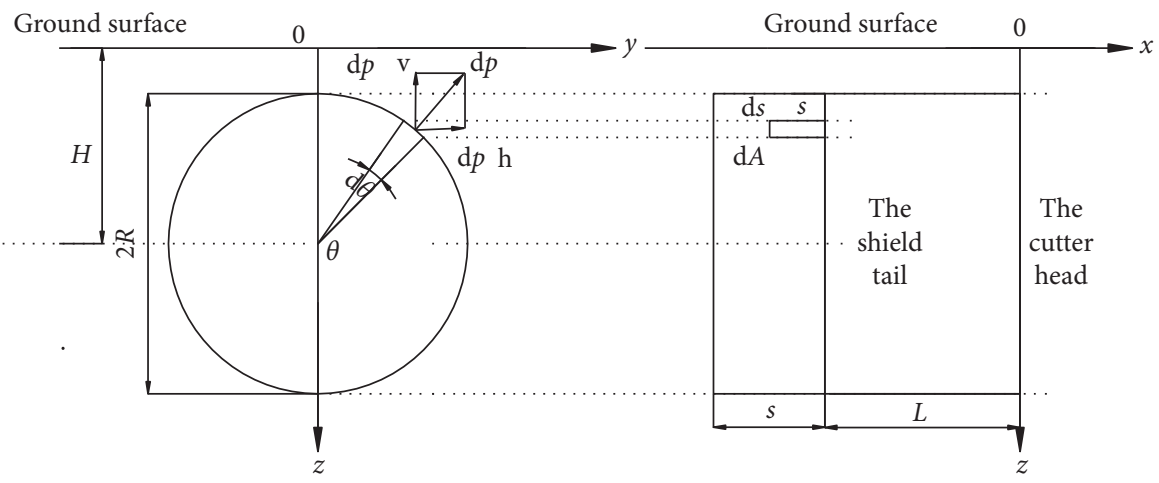

FIGURE 5: The sketch of integration of the grouting pressure.

loss $v_{\text {loss }}$ is $v_{l}=v_{\text {loss }} \cdot \pi R_{t}^{2}$, where $R_{t}$ is the radius of tunnel lining; $r_{1}$ is $\sqrt{y^{2}+(z+H)^{2}} ; r_{2}$ is $\sqrt{y^{2}+(z-H)^{2}} ; R_{11}$ is $\quad \sqrt{y^{2}+(x+L)^{2}+(z+H)^{2}} ; \quad R_{22} \quad$ is $\sqrt{y^{2}+(x+L)^{2}+(z-H)^{2}}$.

However, for the real situation, the presence of the shield body will significantly prevent the deformations transforming from the overexcavated soil volume loss around the tail. Thus, the longitudinal lateral displacements induced by the soil volume loss (12) around the shield tail are assumed as zero.

2.5. Total Lateral Ground Displacements Induced by Shield Tunnelling. Combining the lateral ground displacements induced by the additional pressure of cutter-head $q$, the frictions around shield body $f$, the tail grouting pressure $p$, and the soil volume loss $v_{l}$ during shield advancing, the analytical solutions for predicting the lateral ground displacements in both longitudinal and transversal directions are obtained, respectively. They can be expressed as

$$
\begin{aligned}
& u=u_{1 q}+u_{2 f}+u_{4 v_{l}}, \\
& v=v_{1 q}+v_{2 f}+v_{3 p},
\end{aligned}
$$

where $u$ and $v$ are the lateral ground displacements in longitudinal and transversal directions, respectively.

\section{Cases Studies}

Three previously published well-documented case histories are selected to assess the applicability of the proposed analytical solutions in this section. The measured field data, as well as FEA results, are compared with the predicted results.

3.1. Case 1: San Francisco Tunnel N-2 Contract. A 3.7 m outer diameter earth pressure balanced shield with $5 \mathrm{~m}$ long was employed to the San Francisco Clean Water tunnel project $\mathrm{N}-2$ contract. A $917 \mathrm{~m}$ long, $3.55 \mathrm{~m}$ outer diameter tunnel was constructed in soft, saturated, and low-strength and permeability Bay Mud clay. Field instrumentation program was carefully conducted to observe the response of the ground during and after shield advancement. This well- documented project provides a unique opportunity to study the lateral ground responses to shield construction. The predictions of the longitudinal lateral ground displacements are compared with the measured results, as well as the FEA simulation results.

A subsoil profile is shown in Figure 6. As shown in Figure 6, the tunnel axis was located at the depth of $10.9 \mathrm{~m}$ below the ground surface, which was entirely in the soft saturated stratum, known as recent Bay mud. The overlying and underlying strata were rubble fill with intermediate density and sandy colluvial soil, respectively. Detailed description of the site conditions and the shield tunnelling operation can be referred to Finno and Clough [27] and Clough et al. [12].

Some related parameters obtained from the Finno and Clough [27] are given as follows: based on the site investigation and laboratory tests, the average unit weight of the ground, including the fill ground and the Bay mud, can be taken as $17.6 \mathrm{kN} / \mathrm{m}^{3}$. The undrained shear strength $s_{\mathrm{u}}$ of recent Bay mud is $24.3 \mathrm{kPa}$ at the top of layer and increases linearly with depth at $0.63 \mathrm{kPa} / \mathrm{m}$. The shear modulus $G$ is taken $3.24 \mathrm{MPa}$ for recent Bay mud, which is approximately about 120 times of undrain shear strength $s_{\mathrm{u}}$ according to Hashimoto et al.'s [24] study. Undrained Young' modulus $E_{\mathrm{u}}$ is about $9.72 \mathrm{MPa}$ according to $E_{\mathrm{u}}=2(1+u) G$. Poisson's ratio $u$ is assumed to be 0.5 for the undrained conditions of the soft recent Bay mud clay. The opening ratio of the applied EPB shield $\xi$ and the number of blind slots $k$ are assumed to be $30 \%$ and 3, respectively [27]. The average driving rate $v$ is $9.1 \mathrm{~m} /$ day. The coefficient of earth pressure at rest $K_{0}$ is assumed to be 1 . The angular speed $w$ is assumed to be $3.6 \pi \mathrm{rad} / \mathrm{min}$. The softening coefficient $\beta$ and the interface interior angle $\delta$ are taken as 0.9 and $9^{\circ}$, respectively. Thus, the calculated additional pressure of cutter head is about $24.5 \mathrm{kPa}$. Respecting that the grouting is inefficient in this project, the effects of the tail grouting on the ground are ignored in calculation.

The predicted and observed longitudinal horizontal displacements at $1.22 \mathrm{~m}$ and $2.44 \mathrm{~m}$ front of the shield face are plotted in Figures 6(a) and 6(b), respectively. It is found that the predictions at different distances at the front of the tunnel face are generally in good agreement with the field observations as well as the FEA results, although the predicted results are slightly larger than the observations below 


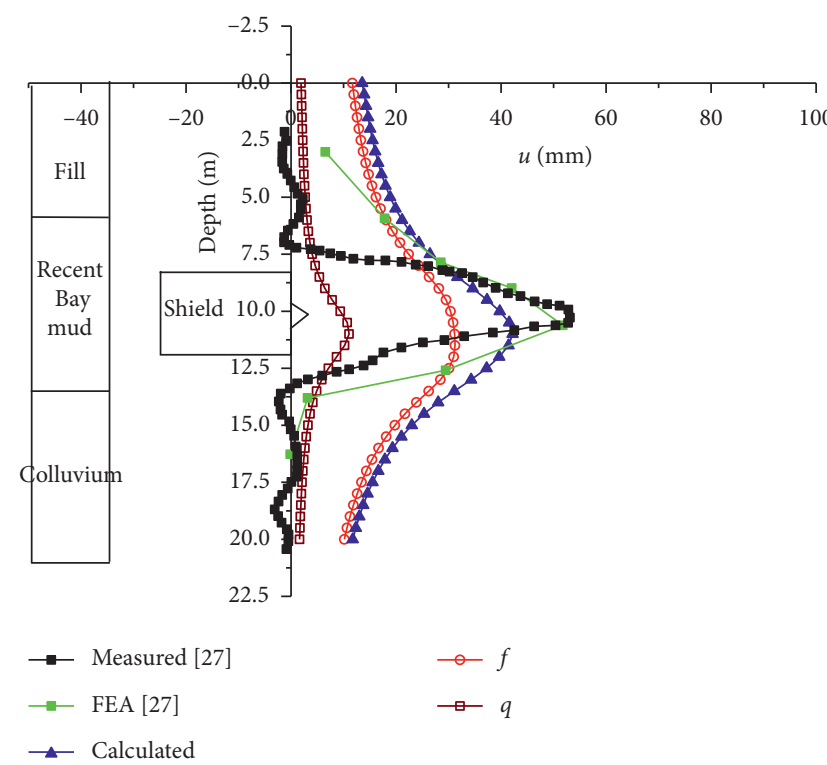

(a)

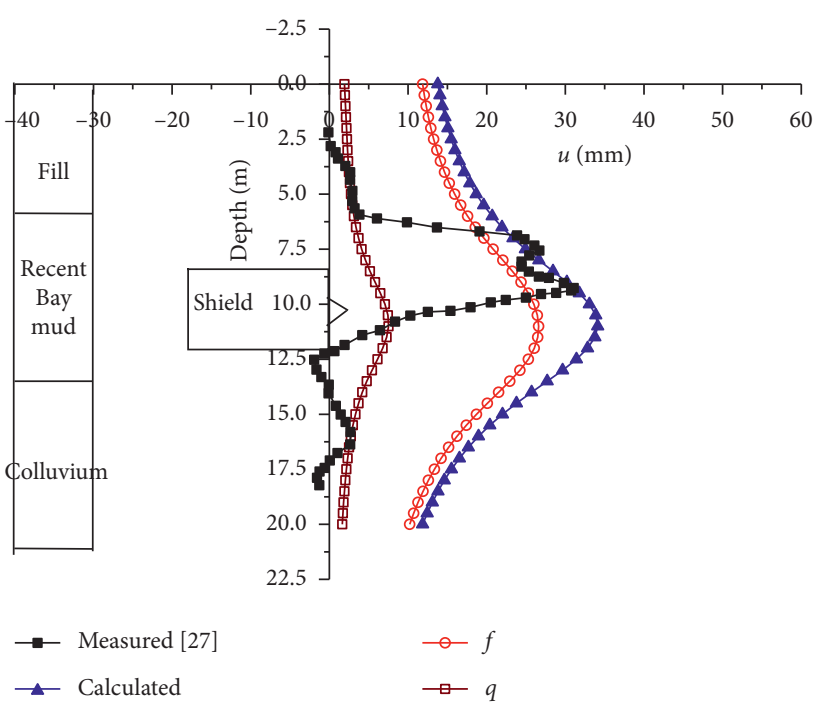

(b)

FIGURE 6: Comparison between the measured and predicted results of lateral ground displacements at the longitudinal direction of shield advancing, San Francisco tunnel N-2 project: (a) $1.22 \mathrm{~m}$ ahead of shield face (b) $2.44 \mathrm{~m}$ ahead of the shield face.

and above the tunnel lining level. It may be attributed to the site conditions where the overlaid rubble fill ground and underlaid colluvial soils would significantly confine the movements of inclinometers. Generally, the prediction accuracy is in an acceptable manner.

From Figures 6(a) and 6(b), it is noted that the lateral displacements contributed by frictions around the shield body $f$ are obviously larger than the contribution of the additional pressure of cutter-head $q$. However, this differs from the common understanding that the additional pressure of cutter-head $q$ contributes a large portion of the displacements. In general, the proposed analytical method can be reasonably used to predict the lateral ground displacements at the longitudinal direction of the advancing shield.

\subsection{Case 2: Shanghai Metro Line-2 Tunnel. Shanghai Metro} Line-2 tunnel was constructed through soft, sensitive, saturated, and low-permeable soft clay by means of an advanced EPB shield machine. A typical soil profile of this project is presented in Figure 7. The responses of the soft ground during and after the advancement of tunnelling machine were carefully monitored. The inclinometer was located at $6.2 \mathrm{~m}$ beside the shield axis and the lateral displacement at transversal direction was monitored. The axis of $6.2 \mathrm{~m}$-diameter tunnel was located at a depth of $15 \mathrm{~m}$ blow the ground surface. The detailed monitoring program and the measurements were well interpreted and discussed by Lee et al. [14].

The main parameters related to the analysis are listed as follows: the outer diameter of the shield $D$ is $6.34 \mathrm{~m}$; the length of the shield $L$ is $6.24 \mathrm{~m}$, the width of the segmental ling $s$ is $1 \mathrm{~m}$; the grouting pressure $p$ is $250 \mathrm{kPa}$; the advancing rate $v$ is $12 \mathrm{~m} / \mathrm{d}$; the equivalent Poisson ratio $u$ is

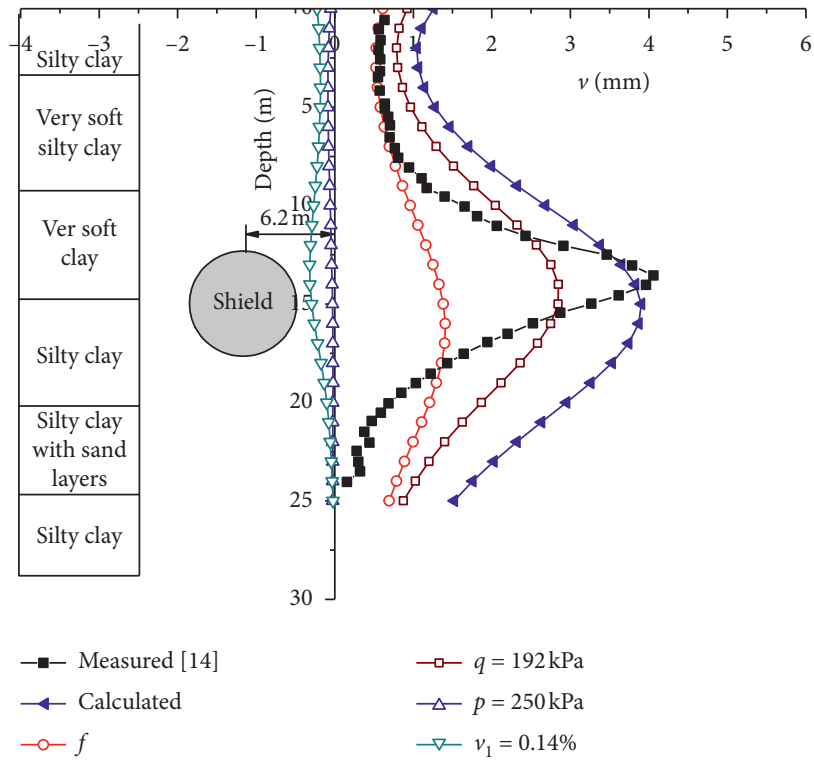

Figure 7: Comparison between the measured and the predicted lateral ground displacements at the transversal direction at the distance of one tunnel diameter ahead of the shield face, Shanghai Metro Line-2 tunnel.

0.35 ; the coefficient of lateral earth pressure $K_{0}$ is 0.57 ; based on the soil investigation, the equivalent undrained Young's modulus of the ground $E_{\mathrm{u}}$ is $9.3 \mathrm{MPa}$, so the equivalent soil shear modulus $G$ is $3.5 \mathrm{MPa}$; the interface internal angel $\delta$ and the softening coefficient $\beta$ is $9^{\circ}$ and 0.9 , respectively; the short-term soil volume loss ratio $v_{1}$ is $0.14 \%$. Based on the related construction experience in Shanghai, the blind bolts of cutter-head $k$, the open ratio $\xi$, and the angel speed $w$ are assumed to be $4,40 \%$, and $0.6 \mathrm{rad} / \mathrm{min}$, respectively. 


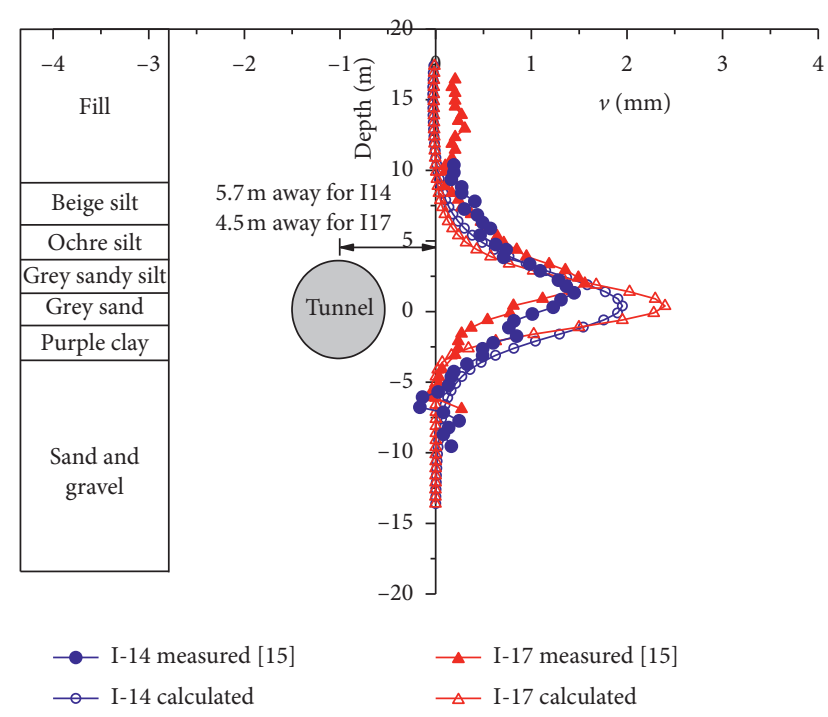

FIGURE 8: Comparison between the measured and predicted lateral ground displacements at the transversal direction at different distance away from the tunnel, France Vaise subway tunnel.

Therefore, the additional pressure of cutter-head $q$ is $192 \mathrm{kPa}$.

The lateral displacements at transversal direction are presented and compared with predictions from the proposed method, as shown in Figure 7. It is observed that the prominent lateral outward deflections are concentrated at the level of shield centerline. As illustrated in Figure 7, the contribution to the calculated displacements is mainly from the additional pressure of cutter-head $q$ and the frictions around the shield body $f$. The calculated lateral displacements at transversal direction below the tunnel invert are slightly larger than the observations. The reason may be due to the assumption of homogenous ground of the proposed method, which indicates the ground movement range is slightly greater that the observation. In general, the predicted lateral ground displacements are in good agreement with the measurements.

3.3. Case 3: France Vaise Subway Tunnel. Extension project of Line D subway network in Lyon, France, was constructed by slurry shield boring machine. The extension tunnel was approximately 1000-m long and had an outer diameter of $6.27 \mathrm{~m}$. The tunnel axis is located at $17.4 \mathrm{~m}$ blow the ground surface, and the shield was mainly excavated through grey sandy slit, grey sand, and purple clay. Geotechnical investigation revealed that the subsurface stratification was relatively nonuniform, as shown in Figure 8 . The lateral displacements were measured by two inclinometers, I14 and I17, located at $5.7 \mathrm{~m}$ and $4.5 \mathrm{~m}$ away from the tunnel axis. Detailed field measuring of lateral soil displacements and site properties are well described and interpreted by Dias and Kastner [15] and Emeriault et al. [28].

The monitored slurry pressure at the shield face was about $120 \mathrm{kPa}$. The grouting pressures varied from $200 \mathrm{kPa}$ to $300 \mathrm{kPa}$. Based on the soil tests results [15], the equivalent
Poisson ratio $u$, shear modulus $G$, and the coefficient of lateral earth pressure $K_{0}$ are assumed to be $0.4,2.5 \mathrm{MPa}$, and 0.57 , respectively. The grouting pressure is assumed to be $280 \mathrm{kPa}$ in this analysis. The interface internal angel $\delta$ and the softening coefficient $\beta$ are $9^{\circ}$ and 0.9 , respectively.

The calculated transversal lateral ground displacements at the inclinometer I14 and I17 are also plotted in Figure 8. The comparison between the measured and predicted results indicates that, although the maximum lateral displacements calculated by proposed method are slightly larger than the observations, the trends of distribution of the calculated results are generally in good agreement with that of the monitored data.

Finally, the feasibility of the proposed analytical method is verified with three case histories. The proposed method takes the additional pressure of cutter head, frictions around the shield body, back-fill grouting pressure, and soil volume loss into account, which will generally reflect the interaction between the shield advancing and ground. The proposed method provides a novel method to predict the lateral ground responses to shield tunnelling.

\section{Conclusions}

(1) In this paper, a simplified analytical method is proposed to predict lateral ground displacements associated with shield tunnelling advancing. Key operation variants, such as the additional pressure of cutter-head $q$, frictions around shield body $f$, the grouting pressure $p$, and the soil volume loss $v_{1}$, are incorporated into the analytical method.

(2) The applicability of the proposed method is verified through with three well-documented case histories involving earth pressure balanced shield and slurry shield. Good agreements have been achieved between the filed measurements and the predictions.

(3) The proposed methods are able to estimate the lateral displacements associated with shield tunnelling.

\section{Data Availability}

Some or all data, models, or codes generated or used during the study are available from the corresponding author upon request (list items).

\section{Conflicts of Interest}

The authors declare no conflicts of interest.

\section{Acknowledgments}

This work was financially supported by National Science Foundation of China (no. 41807262), Shanghai Sailing Program (no. 19YF1421000), Research Project of Shanghai Construction Group Co., Ltd. (no. 19JCYJ-08), China Postdoctoral Science Foundation (no. 2019M653308), and Research Project of Wuhan Municipal Construction Group Co., Ltd. (no. wszky202013). 


\section{References}

[1] R. B. Peck, "Deep excavations and tunnelling in soft ground," in Proceedings of the 7th International. Conference on Soil Mechanics. and Foundation Engineering (Mexico), pp. 225290, Mexico, MX, USA, August 1969.

[2] P. B. Attewell and J. P. Woodman, "Predicting the dynamics of ground settlement and its derivitives caused by tunnelling in soil," Ground Engineering, vol. 15, no. 8, pp. 13-22, 1982.

[3] R. J. Mair, R. N. Taylor, and A. Bracegirdle, "Subsurface settlement profiles above tunnels in clays," Géotechnique, vol. 43, no. 2, pp. 315-320, 1993.

[4] Y.-S. Fang, C.-T. Wu, S.-F. Chen, and C. Liu, "An estimation of subsurface settlement due to shield tunneling," Tunnelling and Underground Space Technology, vol. 44, pp. 121-129, 2014.

[5] C. Sagaseta, "Analysis of undraind soil deformation due to ground loss," Géotechnique, vol. 37, no. 3, pp. 301-320, 1987.

[6] A. Verruijt and J. R. Booker, "Surface settlements due to deformation of a tunnel in an elastic half plane," Géotechnique, vol. 46, no. 4, pp. 753-756, 1996.

[7] N. Loganathan and H. G. Poulos, "Analytical prediction for tunneling-induced ground movements in clays," Journal of Geotechnical and Geoenvironmental Engineering, vol. 124, no. 9, pp. 846-856, 1998.

[8] A. Bobet, "Analytical solutions for shallow tunnels in saturated ground," Journal of Engineering Mechanics, vol. 127, no. 12, pp. 1258-1266, 2001.

[9] A. S. Osman, M. D. Bolton, and R. J. Mair, "Predicting 2D ground movements around tunnels in undrained clay," Géotechnique, vol. 56, no. 9, pp. 597-604, 2006.

[10] A. Franza and A. M. Marshall, "Empirical and semi-analytical methods for evaluating tunnelling-induced ground movements in sands," Tunnelling and Underground Space Technology, vol. 88, pp. 47-62, 2019.

[11] P. Zhang, Z.-Y. Yin, and R.-P. Chen, "Analytical and semianalytical solutions for describing tunneling-induced transverse and longitudinal settlement troughs," International Journal of Geomechanics, vol. 20, no. 8, Article ID 04020126, 2020.

[12] G. W. Clough, B. P. Sweeney, and R. J. Finno, "Measured soil response to EPB shield tunneling," Journal of Geotechnical Engineering, vol. 109, no. 2, pp. 131-149, 1983.

[13] J. R. Standing and D. Selemetas, "Greenfield ground response to EPBM tunnelling in London clay," Géotechnique, vol. 63, no. 12, pp. 989-1007, 2013.

[14] K. M. Lee, H. W. Ji, C. K. Shen, J. H. Liu, and T. H. Bai, "Ground response to the construction of Shanghai metro tunnel-line 2," Soils and Foundations, vol. 39, no. 3, pp. 113-134, 1999.

[15] D. Dias and R. Kastner, "Movements caused by the excavation of tunnels using face pressurized shields-analysis of monitoring and numerical modeling results," Engineering Geology, vol. 152, no. 1, pp. 17-25, 2013.

[16] C. C. Kao, C. H. Chen, and R. N. Hwang, "Mechanism of ground settlements and heaves due to shield tunnelling," Journal of GeoEngineering, vol. 4, no. 2, pp. 63-72, 2009.

[17] K. M. Lee and R. K. Rowe, "An analysis of three-dimensional ground movements: the Thunder Bay tunnel," Canadian Geotechnical Journal, vol. 28, no. 1, pp. 25-41, 1991.

[18] W. N. Yiu, H. J. Burd, and C. M. Martin, "Finite-element modelling for the assessment of tunnel-induced damage to a masonry building," Géotechnique, vol. 67, no. 9, pp. 780-794, 2017.
[19] P. Zhang, R.-P. Chen, H.-N. Wu, and Y. Liu, "Ground settlement induced by tunneling crossing interface of waterbearing mixed ground: a lesson from Changsha, China," Tunnelling and Underground Space Technology, vol. 96, Article ID 103224, 2020.

[20] R. D. Mindlin, "Force at a point in the interior of a semiinfinite solid," Physics, vol. 7, no. 5, pp. 195-202, 1936.

[21] F. Pinto and A. J. Whittle, "Ground movements due to shallow tunnels in soft ground. I: analytical solutions," Journal of Geotechnical and Geoenvironmental Engineering, vol. 140, no. 4, Article ID 04013040, 2014.

[22] J. R. Standing, D. Selemetas, and J. N. Shirlaw, "Greenfield ground response to EPBM tunnelling in London clay," Géotechnique, vol. 64, no. 7, pp. 581-583, 2014.

[23] H. Wang, "Effect of cutterhead compressing the front soil and influence of head aperture ratio on contact pressure of EPB shield to the front soil," China Civil Engineering Journal, vol. 42, no. 7, pp. 113-118, 2009.

[24] T. Hashimoto, J. Nagaya, and T. Konda, "Prediction of ground deformation due to shield excavation in clayey soils," Soils and Foundations, vol. 39, no. 3, pp. 53-61, 1999.

[25] Q. Zhang, S. Li, and L. Li, "Simplified method for settlement prediction of pile groups considering skin friction softening and end resistance hardening," Chinese Journal of Rock Mechanics and Engineering, vol. 32, no. 3, pp. 615-624, 2013.

[26] E. E. Alonso, A. Josa, and A. Ledesma, "Negative skin friction on piles: a simplified analysis and prediction procedure," Géotechnique, vol. 34, no. 3, pp. 341-357, 1984.

[27] R. J. Finno and G. W. Clough, "Evaluation of soil response to EPB shield tunneling," Journal of Geotechnical Engineering, vol. 111, no. 2, pp. 155-173, 1985.

[28] F. Emeriault, D. Breysse, R. Kastner, and A. Denis, "Geotechnical survey and mechanical parameters in urban soils: modelling soil variability and inferring representative values using the extension of Lyon subway line D as a case study," Canadian Geotechnical Journal, vol. 41, no. 5, pp. 773-786, 2004. 